\title{
Referring Physicians' Knowledge on Justification of Medical Exposure in Diagnostic Imaging in a Sub-Saharan African Country, Cameroon
}

\author{
Boniface Moifo, ${ }^{1,2}$, Annick Laure Edzimbi', Haoua Tebere1, Joshua Tambe1, \\ Richard Ndi Samba ${ }^{3}$, Joseph Gonsu Fotsin ${ }^{1,2}$ \\ ${ }^{1}$ Department of Radiology and Radiation Oncology, Faculty of Medicine and Biomedical Sciences, The \\ University of Yaoundé I, Yaoundé, Cameroon \\ ${ }^{2}$ Radiology Department, Yaounde Gynaeco-Obstetric and Pediatric Hospital, Yaounde, Cameroon \\ ${ }^{3}$ National Radiation Protection Agency, Yaounde, Cameroon \\ Email: "bmoifo@yahoo.fr
}

Received 22 November 2013; revised 22 December 2013; accepted 29 December 2013

Copyright $@ 2014$ by authors and Scientific Research Publishing Inc.

This work is licensed under the Creative Commons Attribution International License (CC BY). http://creativecommons.org/licenses/by/4.0/ (c) (9) Open Access

\section{Abstract}

Background: Justification is the process of weighing the potential benefit of the exposure against potential detriment for that individual. Its role has been largely delegated to imaging professionals. Nevertheless, justification process involves referring physicians, radiographers and radiologists. Objective: To assess the knowledge of referring physicians regarding justification of irradiating examinations in medical imaging at the university-affiliated hospitals in Yaoundé Cameroon. Materials and Methods: A questionnaire (18 questions) based on the French guide for the proper use of medical imaging tests in relation to the justification of irradiating examinations, was self-administered to 151 referring physicians in Yaounde (Cameroon) between October 2012 and January 2013. The pre-tested questionnaire was completed in the presence of the investigator. A scoring system was then adopted with a total of 15 points from the level of knowledge on justification which could be classified as satisfactory or not. Results: Referring physicians were 75 (49.7\%) GPs, $53(35.1 \%)$ residents and $23(15.2 \%)$ specialists. Knowledge on justification was unsatisfactory for $\mathbf{7 9 . 5 \%}$ of referring physicians with no significant difference in terms of professional experience ( $p=0.95)$ or specialty $(p=0.119)$. The concepts of "useful exam" and "justified exam" were not known by $113(74.8 \%)$ and $95(62.9 \%)$ practitioners. MRI was selected as irradiating by 62 (41.1\%), SPECT and PET-scan as non-radiating examinations by 98 (64.9\%) and 115 (76.1\%) participants. The main reasons for repeating a giving radiology exam were: unsatisfactory interpreta-

\footnotetext{
"Corresponding author.
}

How to cite this paper: Moifo, B., et al. (2014) Referring Physicians' Knowledge on Justification of Medical Exposure in Diagnostic Imaging in a Sub-Saharan African Country, Cameroon. Open Journal of Radiology, 4, 60-68. 
tion, unknown of where it was performing and poor quality exam respectively for $23(15.2 \%), 37$ $(24.5 \%)$ and $43(28.5 \%)$ referring physicians. Justification was the responsibility of the referring physician alone for $57 \%$ of respondent. Only 11 clinicians knew the reference of "Justification-Optimization-Limitation" to radiation protection. Conclusion: The knowledge of physicians on radiating medical procedures and justification of requests for these procedures is inadequate. Training in radiation protection and the introduction of guidelines for the proper use of imaging tests could improve physicians' justification of radiating examinations.

\section{Keywords}

Assessment; Justification; Referring Physician; Radiation Protection; Best Practices; Cameroon

\section{Introduction}

During the past decades, the extent of radiation exposure of patients has increased very significantly. In some countries, the population dose from medical exposures now rivals that from natural background [1]-[3]. The radiation protection of patients therefore attracts much greater importance. The two principal cornerstones of radiation protection of patients are optimization and justification of exposures [2], [4]-[6].

Justification is the process of weighing the potential benefit of the exposure against potential detriment for that individual. In justification, consideration is taken for the probability that the requested exposures will achieve the desired outcome and whether other exposures, using different techniques or lower doses, or non-ionizing radiating techniques would be suitable instead [7], [8].

Traditionally, the role for justification of radiation procedures has been largely delegated to imaging professionals. But justification process involves both referring physicians, radiographers and radiologists at three different levels: the justification of use of radiation procedure, the justification of a defined radiological technique, the justification of a defined protocol for an individual patient [1], [7]. All examinations in diagnostic radiology shall then be justified to avoid unnecessary irradiation of patients.

Some studies estimated that $20 \%$ to $50 \%$ of CT-scan examinations may not be justified, that the level of knowledge of referring physicians regarding radiation doses in radiological procedures is low and that less than one in three referring doctors received training on radiation protection [1], [9]-[11]. The situation in many developing countries is unlikely to be as much as this [1]. In many Sub-Saharan Africa countries, the practices related to patient radiation protection are poorly documented because of the lack and/or weak enforcement of the related legislative and regulatory frameworks [12]. Some studies on radiation protection in Cameroon established the lack of knowledge of medical imaging professionals on the standards and principles of radiation protection, the lack of continuous professional training on radiation protection, the lack of justification of some radiological procedures, and the absence of "Guide for the Usage of Medical Imaging Procedure" [12]-[14].

With the increased of radiation exposure of patients and multitude of considerations that involves the referral process, clinicians play a greater role in the appropriate choice of investigation and in informed choice of the patient [14]. In our setting, some studies have been conducted concerning knowledge on radiation protection of health professionals working with ionizing radiation [12]-[16], but none on referring physician knowledge regarding justification of the procedures.

As part of a project to improve radiation protection practices of patients, with a view of clinicians' awareness of radiation risks and justification of requested medical imaging procedures, we conducted a survey to assess the knowledge of referring physicians on justification of medical exposure in diagnostic imaging at the university-affiliated hospitals in Yaoundé Cameroon.

\section{Materials and Methods}

The survey was carried out in six university-affiliated hospitals in Yaoundé Cameroon between October 2012 and January 2013 after approval by the Ethics Committee of the Faculty of Medicine and Biomedical Sciences (FMBS) of The University of Yaounde 1. 


\subsection{Participants}

We initially identified 165 referring physicians justifying a request of at least ten medical imaging procedures per week. A planning was established to meet each potential respondent at the hospital or at the FMBS, according to their availability. At each meeting, explanations were provided to respondent as per the objectives of the survey, the confidentiality of the answers and the anonymous nature of the survey form. Once consent obtained, pre-tested questionnaire was auto-administered to the respondent who filled it in the presence of the investigator. Sampling was consecutive and by convenience. Radiologists and Radiologist Residents, illegible or incompletely filled forms were excluded from the study.

\subsection{Questionnaire}

We based on the "Guide for the proper use of medical imaging examinations" [17] of the French Society of Radiology (SFR) to develop the questionnaire. This consisted of a section on the interviewee (gender, qualification, years of experience) and a section on the knowledge and practice of the justification of requested irradiating medical imaging exams. Three questions were focused on the definition of the concepts "useful exam, radiating procedure, justified procedure" and one question required to identify on a list of imaging procedures those that are irradiating. Other questions focused on the responsibility of justification, the daily practices of clinicians about the justification of requested examinations, and the principles of radiation protection.

\subsection{Data Collection and Analysis}

Twelve to fifteen minutes were sufficient for each respondent to complete the questionnaire. Respondent was free to request for clarification from the investigator. The questionnaire was immediately collected after completion and its consecutive number was assigned. A quotation of 15 points was attributed to questions related to definition and practical attitudes regarding justification. A total points (score) from this quotation was used to classify the level of knowledge of respondent as "satisfactory" if total points of 9/15 to 15/15 (60\% to 100\%), and "non-satisfactory" if lower than $9 / 15(<60 \%)$. We then compared the obtained-score to the experience and qualification of the respondents.

Data were analyzed using Epi Info Version 3.5.1 software, Excel 2010 and SPSS Version 20. Means and frequencies were calculated and compared using the chi-square test of Pearson (frequencies) and $\mathrm{T}$ test (means or averages). Difference was considered statistically significant if $p<0.05$ (confidence interval 95\%).

\section{Results}

\subsection{Demographics}

Out of the 165 referring physicians contacted, 151 participated in the survey giving a response rate of $91.5 \%$. There were 83 men (sex ratio 1.2). 75 were general practitioners (49.7\%), 53 residents (35.1\%), and 23 specialists (15.2\%). The mean professional-experience of respondents was $6.8 \pm 4$ years with $43 \%$ of them $(65 / 151)$ having 5 - 9 years of experience.

\subsection{Knowledge of Referring Physicians Regarding Justification of Ionizing Radiating Imaging Examinations}

Knowledge of 31 (20.5\%) referring physicians regarding justification was judged satisfactory (score $\geq 9 / 15$ ). The highest score was 13/15 while the median score confounding to the mode was 7/15. Figure 1 illustrates the distribution of scores obtained by the participants.

We compared the global knowledge on justification between specialists $(n=23)$ and non-specialists $(n=128)$, and to the professional-experience. We founded that the difference between specialists and non-specialists regarding knowledge on justification was not statistically significant $(\mathrm{p}=0.119)$, same as professional-experience $(\mathrm{p}=0.95)$.

\subsection{Knowledge of Referring Physicians Regarding Definition of the Concepts "Useful Exam" "Radiating Exam", “Justified Exam", "Indicated Exam" and "Inadvisable Exam" in Relation with Medical Imaging Exams}

Table 1 shows the proportion of correct answers given by the participants regarding each definition. 


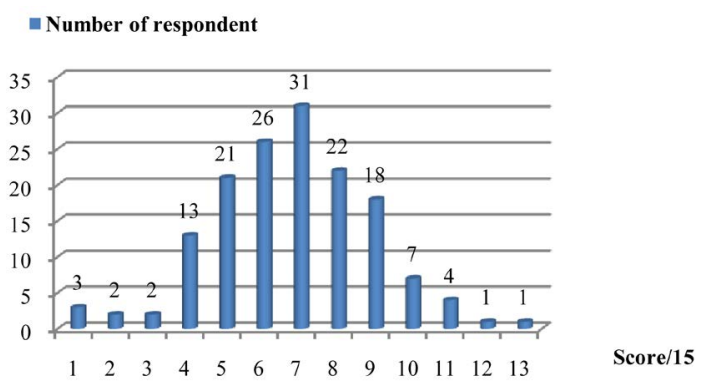

Figure 1. Distribution of scores obtained by respondents regarding knowledge on justification.

Table 1. Answers of participants regarding some definitions..

\begin{tabular}{ccccc}
\hline Definition of concept & Correct (\%) & Incorrect (\%) & Don't know (\%) & Total \\
\hline Useful exam & $38(25.2)$ & $113(\mathbf{7 4 . 8})$ & $0(0.0)$ & 151 \\
Justified exam & $14(9.3)$ & $95(\mathbf{6 2 . 9})$ & $42(27.8)$ & 151 \\
Radiating exam & $108(\mathbf{7 1 . 5 )}$ & $35(23.2)$ & $8(5.3)$ & 151 \\
Indicated exam & $106(\mathbf{7 0 . 2})$ & $44(29.1)$ & $1(0.7)$ & 151 \\
Inadvisable exam & $122(\mathbf{8 0 . 8})$ & $27(17.9)$ & $2(1.3)$ & 151 \\
Average \% & $\mathbf{( 5 1 . 4 )}$ & $\mathbf{( 4 1 . 6 )}$ & $\mathbf{( 7 . 0 )}$ & - \\
\hline
\end{tabular}

Thirty-eight respondents (25.2\%) correctly defined the concept of "useful exam"; out of these, 12 thought that "useful exam" could allow changing the treatment, then giving the complete definition of this concept. The remaining 113 respondents defined "useful exam" as the one which could achieve the diagnosis requirement.

Only 14 (9.3\%) participants correctly defined "justified exam" while 30 participants considered the term "useful” and "justified” as synonyms. 108 respondents defined "radiating exam" as the one using ionizing radiation (31\%) or X-rays (40.5\%). The concept of “indicated exam” was known by $70.2 \%$ of referring physicians compared to $80.8 \%$ of those knowing the definition of "inadvisable exam".

\subsection{Knowledge of Referring Physicians Regarding Radiating Medical Exams}

In the list comprising “Conventional Radiography, Digital Radiography, Ultrasound, MRI, CT-scan, Doppler, Scintigraphy (SPECT), PET-scan”, participants were asked to tick radiating(s) exam(s). MRI and ultrasound were ticked as radiating examinations respectively by 62 (41.1\%) and 4 (2.6\%) participants. The difference was not statistically significant whatsoever the experience ( $p=0.148$ for MRI, $p=0.24$ for ultrasound) or the qualification specialist or non-specialist ( $p=0.34$ for MRI, $p=0.51$ for ultrasound) of the referring physician. Scintigraphy (SPECT) and PET-scan were ticked as non-radiating examinations respectively by 98 (64.9\%) and 115 (76.1\%) participants.

\subsection{Attitudes of Referring Physicians Regarding Requesting and Repeating Radiating Medical Exams}

The reasons for requesting or repeating examinations varied. Before requesting a giving radiating exam $42.4 \%$ (64/151) of participants assumed to make sure that this exam was not already performed, 18.5\% (28/151) admitted to request the same exam even if it was already done, and 6.6\% (10/151) prescribed another exam instead.

The main reasons for repeating a giving radiating exam were: unsatisfactory interpretation, unknown of where it was performing and poor quality exam respectively for 23 (15.2\%), 37 (24.5\%) and 43 (28.5\%) referring physicians.

When referring physicians were not satisfied with the interpretation of a radiating imaging examination, 57\% (86/151) of them admitted to discuss with the radiologist who performed the examination before taking a decision; $18.5 \%$ (28/151) discussed with the radiologist and seek for a second opinion; $11.9 \%$ (18/151) sought for a second opinion; 8.6\% (13/151) repeated that exam in another center and 4\% (6/151) requested another exam instead.

The attitude of referring clinicians when doubting on which exam to request in a giving clinical situation, is shown in Figure 2. 47 (31.12\%) of them considered the advice from their colleagues. 


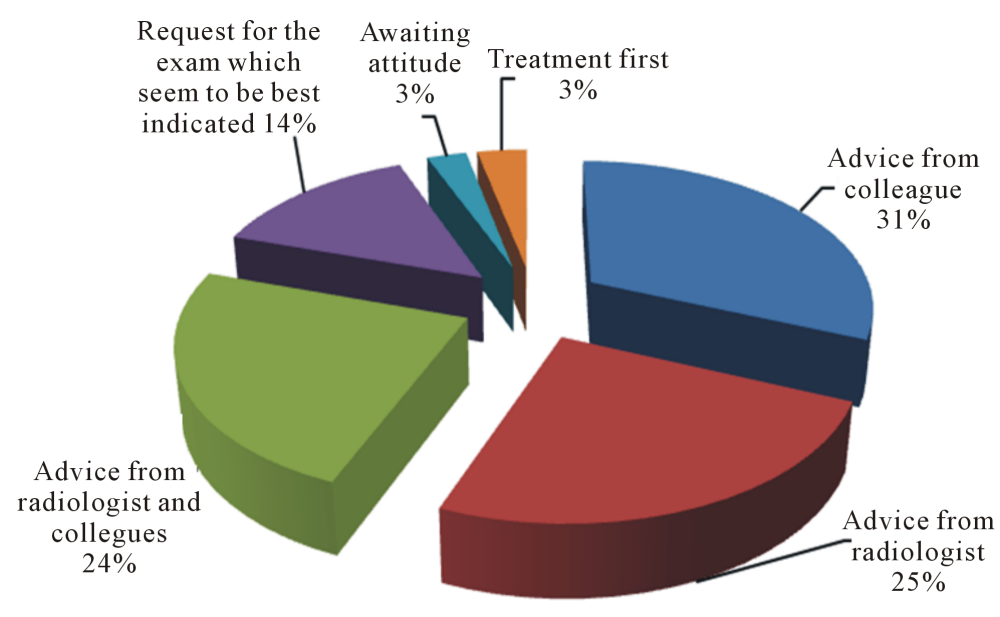

Attitude when doubting on the exam requested

Figure 2. Attitude of referring physicians when doubting on which imaging exam to be requested.

\subsection{The Responsibility for the Justification of Medical Exposure}

As for the question to know who is responsible for the justification of medical exposure, the majority of respondents (86/151) said that justification was the responsibility of the referring physician alone (Figure 3). Concerning the term "justification-optimization-limitation" only 18 interviewees had heard of it and 11 recognized its reference to radiation protection.

\section{Discussion}

\subsection{Data Collection}

Immediate completion of the questionnaire in the presence of the investigator limited the biases subsequent consultation of documents. The anonymity of the questionnaire raised complex related to judgment of an individual respondent. The quotation points of open questions and those related to the practice allowed to have less subjective responses and the possibility of appraising practical attitudes. The predominance of General Practitioners (GPs) is due to the normal distribution of the medical professional population in the country.

\subsection{Level of Knowledge on Radiation Protection, Especially Justification}

We found out that the level of knowledge of referring physicians regarding justification of the request of radiating examinations was not satisfactory (79.5\%). This is consistent with the results of many other studies [9], [18]-[24]. This level of knowledge did not vary with professional experience or qualification. The explanation could be that in our setting there was no initial training during medical studies and no organized continuous education in hospitals on radiation protection. According to Remedios et al. [1], barriers to involvement of clinicians in the process of justification include an already overloaded knowledge base, lack of time, inconsistent guidance and disproportionate patient expectations. They thought that strategies to improve referring physicians' input include education, use of imaging referral guidelines, clinical audit and regulation. In our context, we thought that the following solutions will improve the knowledge of clinicians on the justification of radiating examinations: 1) Provide a guide to good use of imaging tests [17] even if a study from Borgen et al. [21] showed that only $20 \%$ of physicians consulted the guides. 2) Schedule continuing medical education on radiation protection in hospital practice, method proven to be effective by Soye et al. [9]. 3) Integrate in the initial medical training school, courses on radiation protection.

According to O'Sullivan [18] there is a significant difference between students who received training on radiation protection and the control group who did not receive such training. From the analysis of our data, three main information appear: poor knowledge of clinicians on radiation protection especially justification, unjustified repetition of request for radiating medical exams during the same episode of illness, and lack of seeking advices from medical imaging specialists when doubting on the choice of imaging procedure. 
Who is responsible for the justification?

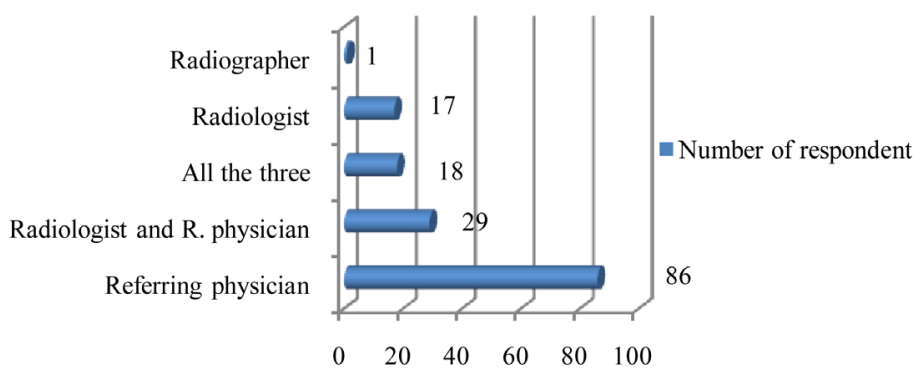

Figure 3. Referring physicians view on the prerogative of justification.

\subsection{Knowledge of Referring Physician Regarding the Concepts of "Useful Exam" "Radiating Exam", "Justified Exam", "Indicated Exam" and "Inadvisable Exam"}

A "useful exam" is an examination which the results, positive or negative, are able to modify the care of the patient, or to reinforce the clinician in the diagnosis [17]. This definition was not properly ticked by $74.8 \%$ of respondents. Some said that a test would only be useful if it could make the diagnosis. The consequence may be an inappropriate request of some medical exams by referring physicians.

Only $9.27 \%$ of participants ticked a correct definition of a "justified medical exam" as an examination that has sufficient direct medical benefit compare to the risk that it may present, and no other technique of comparable efficiency with less risk or without such a risk is not available [17]. The poor knowledge on the two concepts can lead to the absence of clinical information on the request forms for radiating procedure or inappropriate repetition of such procedures during the same episode of illness. This lack of knowledge can be a source of many avoidable patient exposures to irradiation.

\subsection{Knowledge on Radiating Medical Imaging Procedures}

MRI and ultrasound were mistaken to ionizing radiating procedures by $41.1 \%$ and $2.6 \%$ of respondents respectively. Ahidjo et al. [22] and Shiralkar et al. [23] reported higher number of participants classifying MRI as radiating examination (86\% and 92\% respectively). Lower proportions were found by Bilgin et al. [25] and Borgen et al. [21] regarding MRI (27.4\% and 10.5\%) but the ultrasound was taken for radiating examination in their studies in greater proportions ( $4 \%$ and $4.8 \%$ ). Correct answers of $71.6 \%$ to $92 \%$ regarding MRI and of $89.2 \%$ to 96\% regarding ultrasound as non-radiating procedures are founded in the literature [9], [23], [26]-[28]. MRI has been recently introduced in our environment and most clinicians are not yet familiar with this imaging modality.

There was no significant difference of knowledge on radiating procedures according to the experience or the qualification. Heyer et al. [29] and Gumus et al. [28] made the same observation. Gökçe et al. founded a statistically significant difference with respondents over 10 years of experience having less accurate responses [30]. According to Sani et al. that knowledge was better among specialists: $100 \%$ specialists and $88.1 \%$ GPs [31].

Digital radiography, scintigraphy (SPECT) and PET-scan were selected as non-radiating procedures by some of our participants. This can be explained by the fact that PET-scan is not available in our setting while scintigraphy (SPECT) is not popular.

The lack of discrimination between radiating and non-radiating medical imaging procedures can lead to poor justification of procedures. An emphasis should be laid during medical training on the understanding of medical imaging procedures and on the shade regarding justification between radiating and non-radiating exams. Poor knowledge of imaging modalities leads to poor knowledge of imaging possibilities and therefore, misuse of these procedures. According to Remedios et al. [1], strategies to improve referring physicians' input in the process of justification include education, use of imaging referral guidelines, clinical audit and regulation.

\subsection{Reasons of Repeating Medical Imaging Procedures}

The causes of repeating radiating exams were numerous and unjustified: unsatisfactory interpretation, ignorance of where it was performed, or poor quality images. The use of a second opinion radiologist or a discussion with the radiologist who performed the examination reduces unnecessary repetition of examinations. In the same vein, 
when doubting of the appropriate procedure to request for, it is better to refer to a guide of proper use of radiological examinations or to medical imaging professional for the best prescription [17]. In our study $31.12 \%$ clinician referred to their colleague; Merzenich et al. reported $41 \%$ of clinicians who admitted always consult the radiologist prior to the prescription of certain examinations [32].

\subsection{Radiation Protection and Responsibility of Justification}

The responsibility for radiation protection is shared between clinician and medical imaging professional regarding the justification, while optimization and limitation of doses are deserve to medical imaging professional [1], [7], [33]. To minimize exposure, the radiologist must use the lowest possible dose while the clinician must justify the choice of a giving radiating test [33]-[36]. In our study 86 clinicians (57\%) attributed the responsibility of the justification to referring physician alone, but radiographers and radiologists have an important role in the justification of examinations, from the validation of the request from clinicians to the choice of the best protocol suited to a giving patient.

In this study, $88.1 \%$ of respondents were not aware of the basic principles of radiation protection. This reflects a poor knowledge of the principles of radiation protection by our clinicians. The reason being the lack of training of referring physicians on radiation protection [9], [13], [37]. Yet such training improves the knowledge and practice of radiation clinicians [1], [7], [9], [18].

\section{Conclusion}

The level of knowledge on radiating medical procedures and justification of requests for these procedures is inadequate in a context where the use of X-rays is in full expansion. Training in radiation protection and the introduction of guidelines for the proper use of imaging tests adapted to our environment could improve the justification and prescription of irradiating examinations.

\section{Acknowledgements}

To all the participants of this study.

\section{References}

[1] Remedios, D. (2011) Justification: How to Get Referring Physicians Involved. Radiation Protection Dosimetry, 147, 47-51. http://dx.doi.org/10.1093/rpd/ncr263

[2] International Atomic Energy Agency (2009) Report of a Consultation on Justification of Patient Exposures in Medical Imaging. Radiation Protection Dosimetry, 135, 137-144. http://dx.doi.org/10.1093/rpd/ncp107

[3] United Nations Scientific Committee on the Effects of Atomic Radiation (UNSCEAR) (2010) Sources and Effects of Ionizing Radiation. UNSCEAR 2008 Report to the General Assembly, with Scientific Annexes. Vol. 1, United Nations.

[4] ICRP (2007) The 2007 Recommendations of the International Commission on Radiological Protection. ICRP Publication 103. Ann. ICRP, Elsevier.

[5] International Atomic Energy Agency (1996) Basic Safety Standards Series 115.

[6] European Commission (1997) Council Directive 97/43/Euratom of 30 June 1997 on Health Protection of Individuals against the Dangers of Radiation in Relation to Medical Exposure.

[7] Malone, J., Guleria, R., Craven, C., Horton, P., Järvinen, H., et al. (2012) Justification of Diagnostic Medical Exposures: Some Practical Issues. Report of an International Atomic Energy Agency Consultation. British Journal of Radiology, 85, 523-538. http://dx.doi.org/10.1259/bjr/42893576

[8] The Society and College of Radiographers (SCR), The Royal College of Radiologists (RCR), Institute of Physics and Engineering in Medicine (IPEM) (2008) A Guide to Understanding the Implications of the Ionising Radiation (Medical Exposure) Regulations in Radiotherapy. http://www.rcr.ac.uk/docs/oncology/pdf/BFCO083_IRMER.pdf

[9] Soye, J.A. and Paterson, A. (2008) A Survey of Awareness of Radiation Dose among Health Professionals in Northern Ireland. British Journal of Radiology, 81, 725-729. http://dx.doi.org/10.1259/bjr/94101717

[10] Avadanei, C., Rosca-Fartat, G. and Stanescu, G. (2011) Pactitioners Education on Medical Exposure Justification. Radiation Protection Dosimetry, 147, 346-348. http://dx.doi.org/10.1093/rpd/ncr332

[11] Almén, A., Leitz, W. and Richter, S. (2009) National Survey on Justification of CT-Examinations in Sweden. Swedish 
Radiation Safety Authority Report SSM, 3.

http://www.stralsakerhetsmyndigheten.se/Global/Publikationer/Rapport/Stralskydd/2009/SSM-Rapport-2009-03.pdf

[12] Ongolo-Zogo, P., Mpeke Mokubangele, C., Moifo, B. and Gonsu Fotsin, J. (2012) Evaluating Pediatric Patient Dose during Computed Tomography in Two University Teaching Hospitals in Yaoundé-Cameroun. Radioprotection, 47, 533-542. http://dx.doi.org/10.1051/radiopro/2012016

[13] Ongolo-Zogo, P., Nguehouo, M.B., Yomi, J., and Nko’o Amven, S. (2013) Knowledge in Radiation Protection: A Survey of Professionals in Medical Imaging, Radiation Therapy and Nuclear Medicine Units in Yaounde. Radioprotection, 48, 39-49. http://dx.doi.org/10.1051/radiopro/2012017

[14] Moifo, B., Ndeh Kamgnie, M., Fouintama Ninying, F., Gonsu Kamga, J.E. and Gonsu Fotsin, J. (2012) Évaluation de la Conformité des Demandes d’Examens d’Imagerie Médicale: Une Expérience en Afrique Sub-Saharienne. JFR Livres des Résumés, 520-521.

http://jfr.sfrnet.cyim.com/rc/org/sfrnet/htm/Article/2012/20120510-084306-562/src/htm_fullText/fr/JFR\%202012_Livr es\%20des\%20R\%C3\%A9sum\%C3\%A9s.pdf

[15] Muhogora, W.E., Ahmed, N.A., Almosabihi, A., Alsuwaidi, J.S., Beganovic, A., Ciraj-Bjelac, O., Kabuya, F.K., Krisanachinda, A., Milakovic, M., Mukwada, G., Ramanandraibe, M.J., Rehani, M.M., Rouzitalab, M.M. and Shandorf, C. (2008) Patient Doses in Radiographic Examinations in 12 Countries in Asia, Africa and Eastern Europe: Initiela Results from IAEA Projects. American Journal of Roentgenology, 190, 1453-1461. http://dx.doi.org/10.2214/AJR.07.3039

[16] Muhogora, W.E., Ahmed, N.A., Alsuwaidi, J.S., Beganovic, A., Ciraj-Bjelac, O., et al. (2010) Paediatric CT Examinations in 19 Developing Countries: Frequency and Radiation Dose. Radiation Protection Dosimetry, 140, 49-58. http://dx.doi.org/10.1093/rpd/ncq015

[17] Société Française de Radiologie (2005) Guide du bon Usage des Examens d’Imagerie Médicale, Edition 2005. Paris, Editions SFR. http://gbu.radiologie.fr/

[18] O’Sullivan, J., O’Connor, O.J., O’Regan, K., Clarke, B., Burgoyne, L.N., Ryan, M.F. and Maher, M.M. (2010) An Assessment of Medical Students’ Awareness of Radiation Exposures Associated with Diagnostic Imaging Investigations. Insights Imaging, 1, 86-92. http://dx.doi.org/10.1007/s13244-010-0009-8

[19] Zewdneh, D., Teferi Dellie, S. and Ayele, T. (2012) A Study of Knowledge \& Awareness of Medical Doctors towards Radiation Exposure Risk at Tikur Anbessa Specialized Referral and Teaching Hospital, Addis Ababa, Ethiopia. Journal of Pharmacy and Biological Sciences, 2, 1-5. http://dx.doi.org/10.9790/3008-0240105

[20] Hamarsheh, A. and Ahmead, M. (2012) Assessment of Physicians' Knowledge and Awareness about the Hazards of Radiological Examinations on the Health of Their Patients. Eastern Mediterranean Health Journal, 18, 875-881.

[21] Borgen, L., Stranden, E. and Espeland, A. (2010) Clinicians’ Justification of Imaging: Do Radiation Issues Play a Role? Insights Imaging, 1, 193-200. http://dx.doi.org/10.1007/s13244-010-0029-4

[22] Ahidjo, A., Garba, I., Mustapha, Z., Abubakar, A.M. and Usman, U.A. (2012) Referring Doctors Knowledge about Radiation Doses in Patients Undergoing Common Radiological Examinations. Journal of Medicine and Medical Science, 3, 222-225.

[23] Lloyd-Williams, M., Dennis, M., Taylor, F. and Baker, I. (2003) Is Asking Patients in Palliative Care, “Are You Depressed?” Appropriate? Prospective Study. BMJ, 327, 372-373. http://dx.doi.org/10.1136/bmj.327.7411.372

[24] Krille, L., Hammer, G.P., Merzenich, H. and Zeeb, H. (2010) Systematic Review on Physician's Knowledge about Radiation Doses and Radiation Risks of Computed Tomography. European Journal of Radiology, 76, 36-41. http://dx.doi.org/10.1016/j.ejrad.2010.08.025

[25] Arslanoğlu, A., Bilgin, S., Kubal, Z., Ceyhan, M.N., Ilhan, M.N. and Maral, I. (2007) Doctors' and Intern Doctors' Knowledge about Patients’ Ionizing Radiation Exposure Doses during Common Radiological Examinations. Diagnostic and Interventional Radiology, 13, 53-55.

[26] Jacob, K., Vivian, G. and Steel, J.R. (2004) X-Ray Dose Training: Are We Exposed to Enough? Clinical Radiology, 59, 928-934. http://dx.doi.org/10.1016/j.crad.2004.04.020

[27] Lee, C.I., Haims, A.H., Monico, E.P., Brink, J.A. and Forman, H.P. (2004) Diagnostic CT Scans: Assessment of Patient, Physician, and Radiologist Awareness of Radiation Dose and Possible Risks. Radiology, 231, 393-398. http://dx.doi.org/10.1148/radiol.2312030767

[28] Gümüş, C., Cankorkmaz, L., Erkoç, M.F., Öztoprak, B., Atalar, M. and Köylüoğlu, G. (2008) Turkish Pediatric Surgeons Knowledge on the Radiation Exposure of Patients during Diagnostic Imaging. Turkiye Klinikleri Journal of Medical Sciences, 28.

[29] Heyer, C.M., Peters, S., Lemburg, S. and Nicolas, V. (2007) Awareness of Radiation Exposure of Thoracic CT Scans and Conventional Radiographs: What Do Non-Radiologists Know? Rofo, 179, 261-267. http://dx.doi.org/10.1055/s-2006-927366 
[30] Gökçe, S.D., Gökçe, E. and Coşkun, M. (2012) Radiology Residents’ Awareness about Ionizing Radiation Doses in Imaging Studies and Their Cancer Risk during Radiological Examinations. Korean Journal of Radiology, 13, 202-209. http://dx.doi.org/10.3348/kjr.2012.13.2.202

[31] Sani, K.G., Jafari, M., Mohammadi, M., Mojiri, M. and Rahimi, A. (2009) Iranian Physicians’ Knowledge about Radiation Dose, Received by Patients in Diagnostic Radiology. Iranian Journal of Radiation Research, 6, 207-212.

[32] Merzenich, H., Krille, L., Hammer, G., Kaiser, M., Yamashita, S. and Zeeb, H. (2012) Paediatric CT Scan Usage and Referrals of Children to Computed Tomography in Germany: A Crosssectional Survey of Medical Practice and Awareness of Radiation Related Health Risks among Physicians. BMC Health Services Research, 12, 47. http://dx.doi.org/10.1186/1472-6963-12-47

[33] Agostini, S., André, M., Bartoli, J.M., Bourlière, B., and Chagnaud, Ch., et al. (2007) Indications et Stratégies d’Utilisation des Principaux Examens de Radiologie (5).

[34] Gervaise, A., Teixeira, P., Villani, N., Lecocq, S., Louis, M. and Blum, A. (2013) CT Dose Optimisation and Reduction in Osteoarticular Disease. Diagnostic and Interventional Imaging, 94, 371-388. http://dx.doi.org/10.1016/j.diii.2012.05.017

[35] Ducou le Pointe, H. (2013) Computed Tomography and Radioprotection: Knowing and Acting. Diagnostic and Interventional Imaging, 94, 361-363. http://dx.doi.org/10.1016/j.diii.2013.03.015

[36] Ferretti, G. and Jankowski, A. (2010) Radiation Doses of Radiological Examinations of the Thorax. Revue des Maladies Respiratoires, 27, 644-650. http://dx.doi.org/10.1016/j.rmr.2010.03.024

[37] Keijzer, G.B. and Britton, C.J. (2010) Doctors’ Knowledge of Patient Exposure from Diagnostic Imaging Requested in the Emergency Department. Medical Journal of Australia, 193, 450-453. 